\title{
Theropod dinosaurs from the Upper Cretaceous of the South Pyrenees Basin of Spain
}

Angelica Torices, Philip J. Currie, Jose Ignacio Canudo, and Xabier Pereda-Suberbiola Acta Palaeontologica Polonica 60 (3), 2015: 611-626 doi: http://dx.doi.org/10.4202/app.2012.0121

The dinosaur record in the South Pyrenees Basin is diverse and rich. A total of 142 theropod teeth were studied for this paper, which constitutes one of the richest samples for these remains in Europe. Eight upper Campanian to upper Maastrichtian outcrops from the Pyrenees produced six non-avian theropod taxa (Theropoda indet., Coelurosauria indet., ?Richardoestesia, ?Dromaeosauridae indet., ?Pyroraptor olympius, ?Paronychodon). These six taxa are added to two previously described theropods (a Richardoestesia-like form and a possible ornithomimosaurid), indicating that there was considerable theropod diversity on the Iberian Peninsula during the Late Cretaceous.

Key words: Dinosauria, Theropoda, teeth, Cretaceous, Spain, South Pyrenees.

Angelica Torices [torices@ualberta.ca] and Philip J. Currie [philip.currie@ualberta.ca

], Department of Biological Sciences, University of Alberta, CW 405 Biological

Sciences Centre, Edmonton, Alberta, Canada; José Ignacio Canudo [jicanudo@unizar.es

], Grupo Aragosaurus - IUCA, Paleontología, Facultad de Ciencias, Universidad de Zaragoza, Pedro Cerbuna 12, 50009 Zaragoza, Spain; Xabier

Pereda-Suberbiola [xabier.pereda@ehu.es], Universidad del País Vasco/Euskal Herriko Unibertsitatea (UPV/EHU), Facultad de Ciencia y Tecnología, Dpto. Estratigrafía y Paleontología, Apdo. 644, 48080 Bilbao, Spain.

This is an open-access article distributed under the terms of the Creative Commons Attribution License (for details please see creativecommons.org), which permits unrestricted use, distribution, and reproduction in any medium, provided the original author and source are credited. 
Farf Full text $(712.2 \mathrm{kB})$

Forf Supplementary file $(122.6 \mathrm{kB})$ 